For publication in the Proceedings of the Fourth International Laser Science Conference (ILS-IV) (Advances in Laser Sciences - IV) Mariott Marquis Hotel, Atlanta, Georgia, October 2-6, 1988, to be published by the American Institute of Physics

\title{
MULTIPHOTON IONIZATION PHOTOELECTRON SPECTROSCOPY OF XENON: EXPERIMENT AND THEORY*
}

\author{
S. J. Bajic and R. N. Compton \\ Chemical Physics Section, Oak Ridge National Laboratory, \\ Oak Ridge, Tennessee 37831-6125 \\ and Department of Chemistry, The University of Tennessee \\ Knoxville, Tennessee 37996 \\ X. Tang, A. L'Huiller, and P. Lambropoulos \\ Department of Physics, University of Southern California \\ Los Angeles, California 90089
}

CONF-881002--32

DE89 004182

\begin{abstract}
November 1988
"The submitted manuscript has been suthored by a contractor of the U.S Government under contract ACO5-84OR21400. Accordingly, the U.S. Government retaine nonexclugive, royalty-free license to publish or reproduce the published form of this contribution, or allow others to do so, for U.S. Government purposes." with Martin Marietta Energy Systems, Inc.
\end{abstract}

*Research sponsored by the Office of Health and Environmental Research, U.S. Department of Energy under contract DE-AC84OR21400

\section{DISCLAIMER}

This report was prepared as an account of work sponsored by an agency of the United Stales Government. Neither the United States Government nor any agency thereof, nor any of their employees, makes any warranty, express or implied, or assumes any legal liability or responsibility for the acsuracy, completeness, or usefulness of any information, apparatus, product, or process disclosed, or represents that its use would not infringe privately owned rights. Reference herein to any specific commercial product, process, or service by trade name, trademark, manufacturer, or otherwise does not necessarily constitute or imply its endorsement, recommendation, or favoring by the United States Government or any agency thereof. The views and opinions of authors expressed herein do not necessarily state or reflect those of the United States Government or any agency thereof. 


\title{
MULTIPHOTON IONIZATION PHOTOELECTRON SPECTROSCOPY OF XENON: EXPERIMENT AND THEORY
}

\author{
S. J. Bajic and R. N. Compton \\ Oak Ridge National Laboratory, Oak Ridge, Tennessee 37831-6125 \\ and Department of Chemistry, The University of Tennessee \\ Knoxville, Tennessee 37996 \\ X. Tang, A. L'Huiller, and P. Lambropoulos \\ Department of Physics, University of Southern California, \\ Los Angeles, California 90089
}

\section{ABSTRACT}

Photoelectron energy and angular distributions for resonantly enhanced multiphoton ionization (REMPI) of xenon via the three-photon-allowed $7 \mathrm{~s}\left[\frac{3}{2}\right]_{1}^{0}$ and $5 \mathrm{~d}\left[\frac{3}{2}\right]_{1}^{0}$ states have been studied both experimentally and theoretically. The electron kinetic energy spectra give the probability of leaving $\mathrm{Xe}^{+}$in either the ${ }^{2} \mathrm{P}_{1 / 2}$ or ${ }^{2} \mathrm{P}_{3 / 2}$ core. The measured branching ratio for leaving each ionic core is used to test the theoretical description of the REMPI process. Measurements of both the angular distributions and the [3+1] REMPI via the $5 \mathrm{~d}$ state are adequately reproduced by multichannel quantum defect theory. However, measurements of angular distributions for the electrons resulting from $[3+1]$ via the $7 \mathrm{~s}\left[\frac{3}{2}\right]_{1}^{0}$ state into $\mathrm{Xe}^{+}{ }^{2} \mathrm{P}_{3 / 2}$ (core preserving) or $\mathrm{Xe}^{+{ }^{2}} \mathrm{P}_{1 / 2}$ (core changing) are in striking disagreement with theorx.

\section{INTRODUCTION}

Coupling experimental and theoretical studies of REMPI and photoelectron spectroscopy (PES) can provide unique information about the photoionization dynamics of excited states. REMPI-PES studies of the rare gases have mostly been confined to xenon primarily because the lowest Rydberg states are easily accessible using available lasers. Recently, Blazewicz et al. ${ }^{1}$ have shown that multichannel quantum defect theory (MQDT) can provide an excellent description of the [3+2] and [3+1] REMPI processes via the Xe $6 s\left[\frac{3}{2}\right]_{1}^{0}$ and $6 s^{\prime}\left[\frac{1}{2}\right]_{1}^{0}$ states, respectively. We have extended this work to the $7 \mathrm{~s}\left[\frac{3}{2}\right]_{1}^{0}$ and $5 \mathrm{~d}\left[\frac{3}{2}\right]_{1}^{0}$ states of xenon. The apparatus for this experiment has been described elsewhere ${ }^{1}$ and will not be discussed here.

\section{RESULTS}

Figure 1 shows the energy distribution of the photoejected electrons for the $[3+1]$ REMPI process via the $5 \mathrm{~d}\left[\frac{3}{2}\right]_{1}^{0}$ level of Xe at $357.6 \mathrm{~nm}$. Electrons with an energy of $1.7 \mathrm{eV}$ dominate the spectrum. This corresponds to a noncore-changing ionization process. In addition, a small signal at $0.4 \mathrm{eV}$ is seen which corresponds to photoelectrons leaving the $\mathrm{Xe}^{+}{ }^{2} \mathrm{P}_{1 / 2}$ ionic core. The approximate ratio of the two observed signals is comparable with that predicted from MQDT calculations. Figure 1 also shows the polar plot of the measured angular distribution for the electrons resulting from REMPI via the

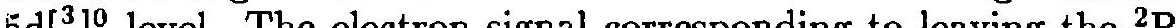


too weak to obtain a reliable angular distribution measurement. Fitting the angular distribution data to a Legendre polynomial expansion required terms up to $\mathrm{P}_{8}(\cos \theta)$ :

$$
\mathrm{Xe}^{+{ }^{2} \mathrm{P}_{3 / 2}: \mathrm{I}(\theta)=1+1.23 \mathrm{P}_{2}+0.75 \mathrm{P}_{4}+0.20 \mathrm{P}_{6}-0.70 \mathrm{P}_{8}}
$$

The calculated angular distribution from MQDT for the ${ }^{2} \mathrm{P}_{3 / 2}$ electrons quantitatively reproduces the angular distribution observed in the experiment.
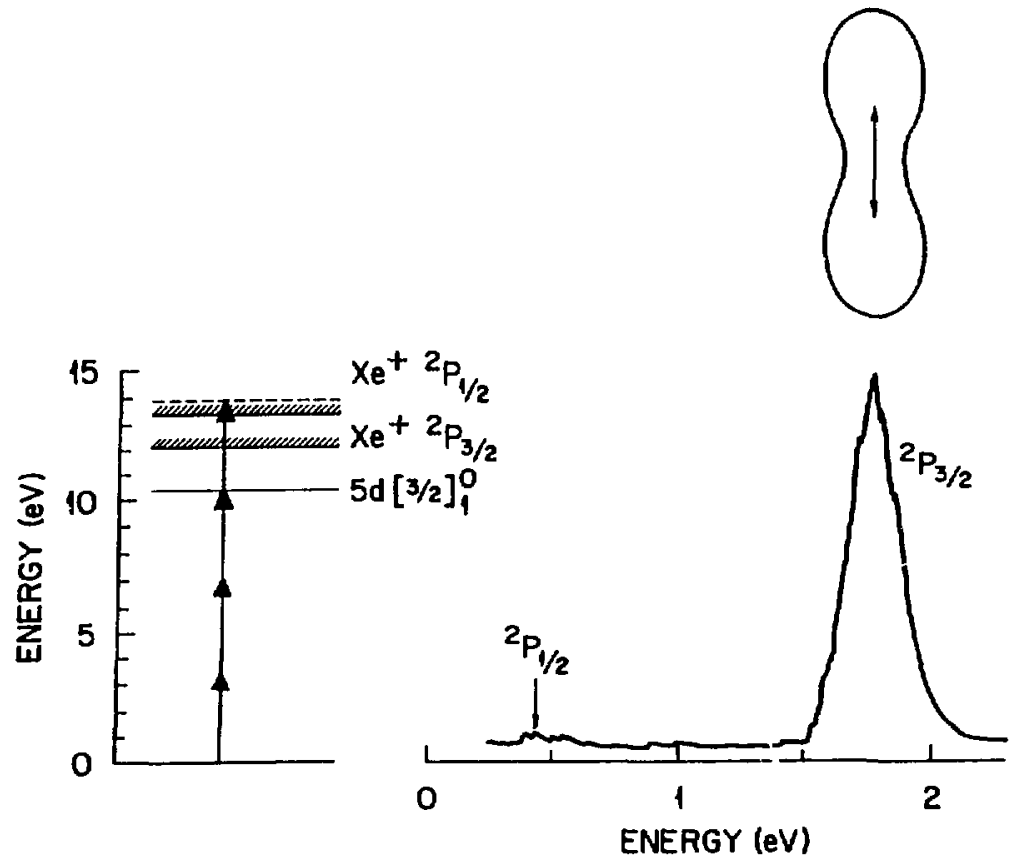

Figure 1. PES and angular distribution for REMPI via the 5d state.

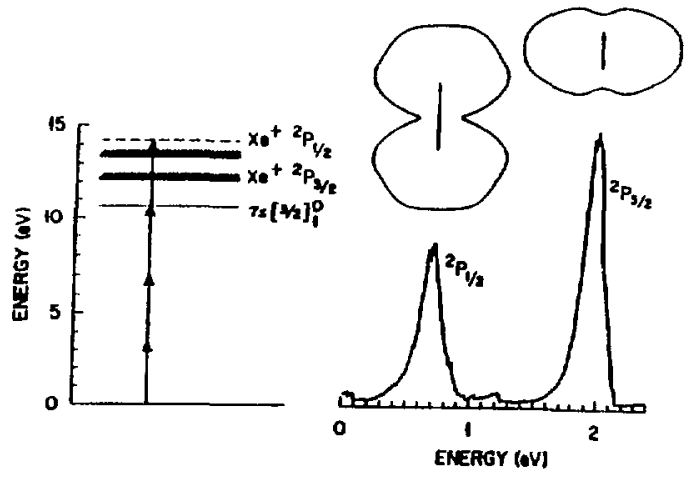

Figure 2. PES and angular distributions for REMPI via the $7 \mathrm{~s}$ state.
Figure 2 shows the energy distribution of the photoelectrons for the $[3+1]$ REMPI process through the $7 \mathrm{~s}\left[\frac{3}{2}\right]_{1}^{0}$ state of $\mathrm{Xe}$ at $351.1 \mathrm{~nm}$. Two groups of electrons are observed at 0.7 $\mathrm{eV}$ and $2.0 \mathrm{eV}$ which correspond to leaving the $\mathrm{Xe}^{+2} \mathrm{P}_{1 / 2}$ and ${ }^{2} \mathrm{P}_{3 / 2}$ ionic cores respectively. The ratio of the two signals (approx. 2:1) compares favorably with that predicted from MQDT.

The polar plots of the experimental angular distribution for the two groups of electrons are shown above their respective energy distributions. As can be seen, the two groups yield quite different angular distributions. The experimental angular distributions were also fitted to a Legendre polynomial 
expansion. It was found that terms up to $\mathrm{P}_{8}(\cos \theta)$ were needed to fit both the ${ }^{2} \mathrm{P}_{1 / 2}$ and ${ }^{2} \mathrm{P}_{3 / 2}$ data.

$$
\begin{array}{ll}
\mathrm{Xe}^{+2} \mathrm{P}_{3 / 2}: & \mathrm{I}(\theta)=1-0.33 \mathrm{P}_{2}+0.02 \mathrm{P}_{4}-0.03 \mathrm{P}_{6}-0.04 \mathrm{P}_{8} \\
\mathrm{Xe}^{+2} \mathrm{P}_{1 / 2}: & \mathrm{I}(\theta)=1+0.78 \mathrm{P}_{2}-0.42 \mathrm{P}_{4}+0.30 \mathrm{P}_{6}-0.16 \mathrm{P}_{8}
\end{array}
$$

MQDT calculations semiqualitatively agree with the general shape of the experimental angular distribution for the ${ }^{2} \mathrm{P}_{1 / 2}$ electrons except for a predicted small maxima at $\pi / 2$ where a sharp minima is observed in the experiment. MQDT calculations predict that the angular distribution for the ${ }^{2} \mathrm{P}_{3 / 2}$ corepreserving electrons should have a deep and somewhat broad minima at $\pi / 2$ and a maxima at 0 and $\pi$. However the experiment shows that the angular distribution is somewhat isotropic with an unexpected maxima at $\pi / 2$ and minima at 0 and $\pi$. This discrepancy is not understood at this time.

Research sponsored by the Office of Health and Environmental Research, U.S. Department of Energy under contract DE-AC05-84OR21400 with Martin Marietta Energy Systems, Inc.

\section{REFERENCE}

1. P. R. Blazewicz, X. Tang, R. N. Compton, and J.A.D. Stockdale, J. Opt. Soc. Am. B., $\underline{4}(5), 770$ (1987). 